\title{
Gated SPECT Myocardial Perfusion Imaging in female patients - an observational study
}

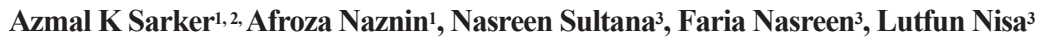 \\ ${ }^{1}$ Institute of Nuclear Medicine and Allied Sciences (INMAS), Mitford, SSMC campus, Dhaka \\ ${ }^{2}$ Institute of Nuclear Medical Physics (INMP), AERE campus, Savar, Dhaka \\ ${ }^{3}$ National Institute of Nuclear Medicine and Allied Sciences (NINMAS), BSMMU campus, Shahbag, Dhaka, 1000.
}

Correspondence Address: Dr. Azmal K Sarker, Senior Medical Officer, INMAS, Mitford Dhaka-1100 \& INMP, Savar, Bangladesh. aksninmas@gmail.com

\begin{abstract}
Background: It had been a general observation that the number of female patients undergoing SPECT myocardial perfusion imaging (MPI) is lower per week.This study was done to find out their proportionand association among their symptoms, history of (h/o) acute coronary syndrome (ACS) and corresponding myocardial perfusion.

Patients and methods: This cross sectional retrospective study was conducted in 2017 on a group of patients who underwent gated SPECT myocardial perfusion imaging (GSMPI)from February 2005 to October 2016. Clinical record files and image files of all female patients were selected for analysis. The symptoms were retrospectively categorized according to New York Heart Association (NYHA) class while the patients were categorized according to their $\mathrm{h} / \mathrm{o}$ ACS and myocardial perfusion in each patient was categorized as normal or perfusion defect. Data were analyzed using SPSS v.20.
\end{abstract}

Results:Among 1347 patients undergoing GSMPI 196 (14.6\%) were female with a 4.4-fold increase in number over 12 years. Mean age was $51.8 \pm 10.1$ (27-80). Symptom categorization assigned 84 patients in NYHA class I and 112 in NYHA class II. There was no h/o ACS in 143 while 53 had a previous h/o hospitalization due to ACS. GSMPI revealed normal perfusion in 156 patients with mean left ventricular ejection fraction (LVEF) of $66.6 \pm 13.6$. Perfusion defect was present in 40 patients with mean LVEF of $45.5 \pm 15.8$. NYHA class of symptoms was not associated with perfusion status $(\mathrm{p}>0.05) . \mathrm{H} / \mathrm{o}$ ACS was found to have association both with NYHA class of symptoms and with perfusions status $(\mathrm{p}<0.05)$.

Conclusions: Proportion of female patients undergoing GSMPI is low. Presence of perfusion defect in female was not associated with NYHA class of symptom.

Key words: Myocardial perfusion imaging, gated SPECT, female, perfusion defect, LVEF, symptom.

Bangladesh J. Nucl. Med. Vol. 22 No. 2 July 2019

Doi: https://doi.org/10.3329/bjnm.v22i2.51759

\section{INTRODUCTION}

Ischemic heart disease (IHD) in women has unique manifestations of symptoms, distribution of prevalence and, complex underlying pathophysiology (1). With an increasedrisk of obstructive coronary artery disease (CAD) in women, hospitalization with ST-segment elevation acute coronary syndrome (ACS) have higher in-hospital mortality (1) as well as a poor peri-procedural outcome (2). This warrants a smart use of screening and diagnostic tools for better prevention and efficient treatment of cardiovascular disease (CVD) in women (3).

While the CVD prevalence is on a steady rise for the last four decades, both genders are being equally affected by the disease (4). Gated SPECT myocardial perfusion imaging (GSMPI) has been aiding the management of CAD for the past two decades in Bangladesh (5). It has been generally observed that the proportion of females is relatively lower per week among the patients undergoing GSMPI at the National Institute of Nuclear Medicine \& Allied Sciences (NINMAS). This study was done first, to find out their proportion over the past years and then, to find an association among their presenting symptom categorized as the New York Heart Association (NYHA) class, history of h/o acute coronary syndrome (ACS), and corresponding myocardial perfusion status.

\section{PATIENTS AND METHODS}

This cross sectional retrospective study was conducted in 2017. Study population was a group of patients who were referred to Nuclear Cardiology Division of NINMAS from February 2005 to October 2016 for GSMPI. Clinical record files and image files of all female patients were selected from the divisional archivefor the purpose of reviewing and inclusion in the study. All relevant demographic and clinical data were documented. Presenting symptom of each patient were retrospectively categorized according to NYHA class. Patients were further categorized in to two groups 
according to their $\mathrm{h} / \mathrm{o}$ ACS. Then perfusion was categorized as normal perfusion and perfusion defect which comprised ischemia, infarction and a combination of both. Data were analyzed using SPSS v.20. Continuous data were presented as means and standard deviations (SD) and value ranges. Categorical data were presented as frequencies and percentages. Chi square test of association was done where a p-value of $<0.05$ was considered to be significant.

\section{RESULTS}

During the time span of 608 weeks, total 1347 patients underwent GSMPI at NINMAS. Among them 196 $(14.6 \%)$ were female with a mean age of $51.8 \pm 10.1$ (27-80) years. Figure 1 shows a 4.4 -fold increase in the number of female patients undergoing GSMPI at NINMAS over the study period. Table 1 shows clinical characteristics among the study patients.

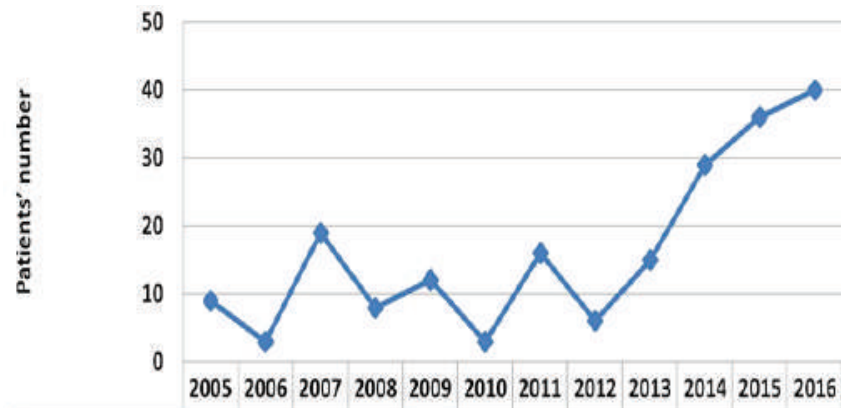
\begin{tabular}{|l|l|l|l|l|l|l|l|l|l|l|l|l|}
\hline A Female patients & 9 & 3 & 19 & 8 & 12 & 3 & 16 & 6 & 15 & 29 & 36 & 40 \\
\hline
\end{tabular}

Figure 1: Temporal change in the number of female patients undergoing GSMPI per year at NINMAS over a period of 12 years
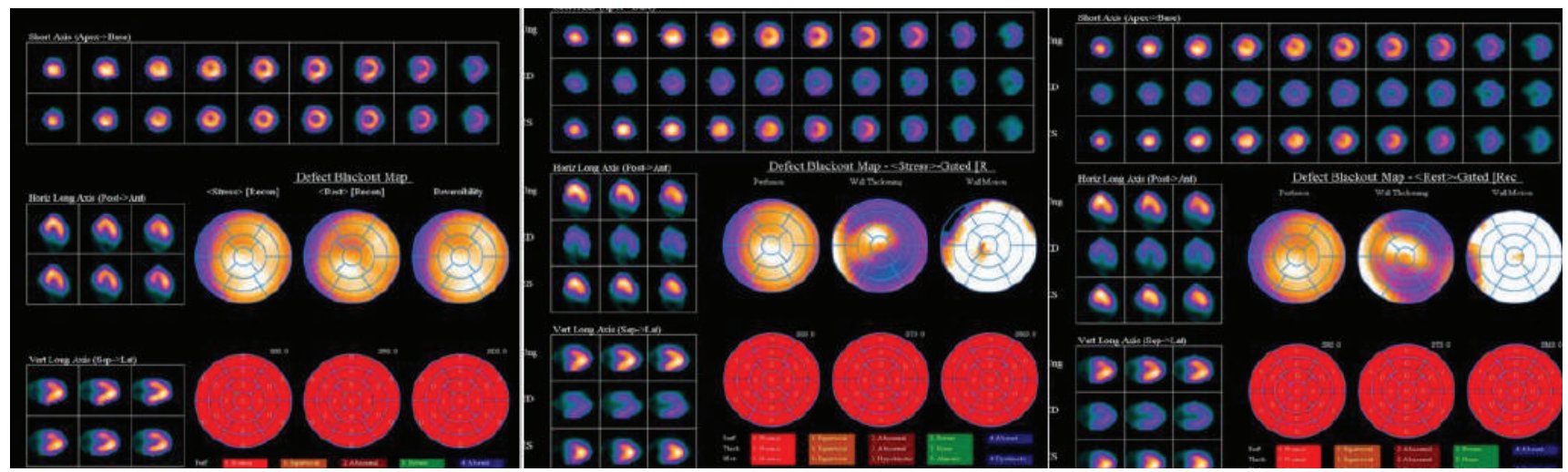

Figure 2: Representative case of NYHA class II symptom but non-obstructive CAD. Post stress and rest GSMPI images in a 45 years old female with history of hospital management as a case of ACS with normal rest ECG, echocardiogram \&troponin I level; being unable to undergo exercise ECG, underwent pharmacological stress GSMPI to reveal normal myocardial perfusion with normal global wall motion and thickening with LVEF $>60 \%$

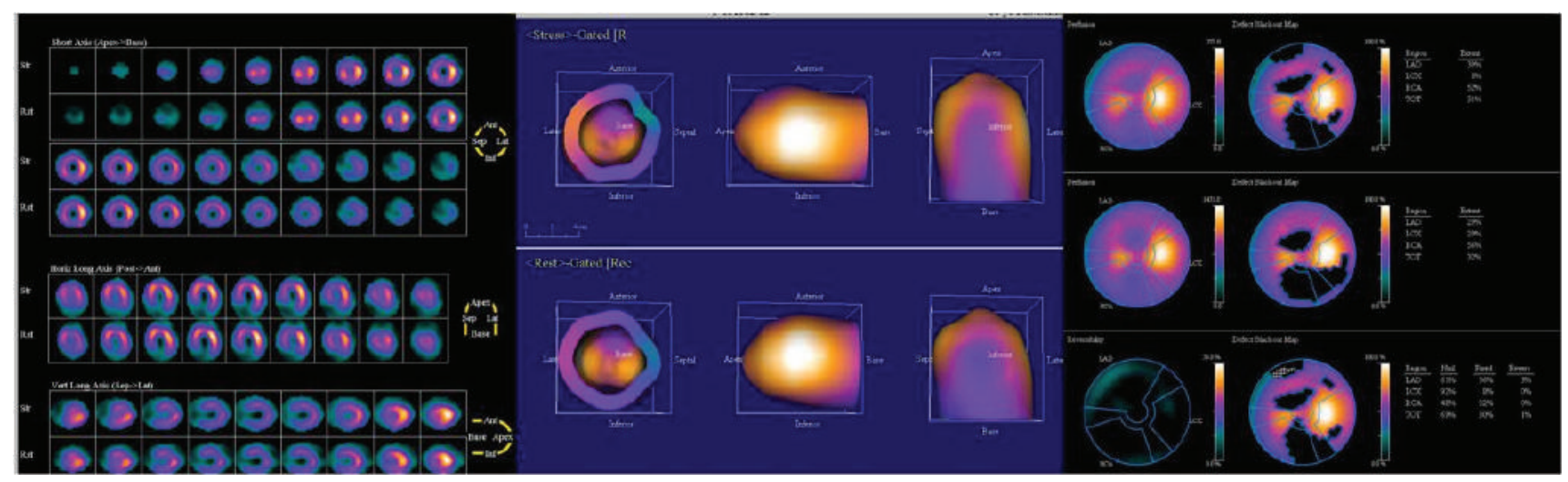

Figure 3: Representative case of NYHA class I symptom with microvascular dysfunction. Post stress and rest GSMPI images in a 55 years old female. With $>10$ years'history of uncontrolled diabetes mellitus, she was found to have inferior wall hypokinesia and LVEF of $\mathbf{4 0 \%}$ during an echocardiogram as a part of routine check-up; being unable to undergo exercise ECG, underwent pharmacological stress GSMPI to reveal fixed perfusion defects over triple vessel's territory affecting $30 \%$ of total myocardium. EDV and EF were $156 \mathrm{ml}$ and $45 \%$ at stress and $133 \mathrm{ml}$ and $37 \%$ at rest. 
GSMPI revealed normal perfusion in 156 patients. As shown in figure 2, a representative post stress and rest GSMPI images of a 45 years old female who with a history of hospital management as a case of acute coronary syndrome and rest ECG, echocardiogram and troponin I all within normal limits, being unable to undergo exercise ECG, underwent pharmacological stress GSMPI to reveal normal myocardial perfusion with normal global wall motion and thickening with LVEF $>60 \%$. Perfusion defect, comprising of ischemia or infarction or both together were seen in 40 patients.

Figure 3 shows a representative post stress and rest GSMPI images in a 55 years old female. With $>10$ years history of uncontrolled diabetes mellitus, she was found to have inferior wall hypokinesia and LVEF of $40 \%$ during an echocardiogram as a part of routine check-up; being unable to undergo exercise ECG, underwent pharmacological stress GSMPI to reveal fixed perfusion defects over triple vessels territory affecting 30\% of total myocardium. EDV and EF were $156 \mathrm{ml}$ and $45 \%$ at stress and $133 \mathrm{ml}$ and $37 \%$ at rest.

Table 1: Clinical characteristics among the study patients

\begin{tabular}{|c|c|c|c|c|}
\hline Traits & Frequency & Age & $\begin{array}{l}\text { GSMPI LVEF } \\
\text { at rest }\end{array}$ & $\begin{array}{l}\text { GSMPI LVEF } \\
\text { at stress } \\
\end{array}$ \\
\hline \multicolumn{5}{|l|}{ Coronary Angiogram } \\
\hline Triple vessel disease & 18 & $55.2 \pm 10.1$ & $52.3 \pm 19.2$ & $52.7 \pm 17.9$ \\
\hline Double vessel disease & 14 & $58.4 \pm 8.9$ & $55.2 \pm 18.2$ & $56.6 \pm 14.5$ \\
\hline Single vessel disease & 29 & $48.9 \pm 10.3$ & $54.4 \pm 15.7$ & $57.8 \pm 20.5$ \\
\hline Normal & 12 & $47.1 \pm 13.1$ & $67.3 \pm 12.3$ & $68.1 \pm 10.3$ \\
\hline Not done & 123 & $51.8 \pm 9.4$ & $65.7 \pm 15.2$ & $68.9 \pm 14.9$ \\
\hline \multicolumn{5}{|l|}{$\begin{array}{l}\text { Previous Coronary } \\
\text { Revascularization }\end{array}$} \\
\hline Thrombolysis & 03 & $53.3 \pm 13.6$ & $46.0 \pm 22.7$ & $38.3 \pm 21.4$ \\
\hline Cardiac surgery & 10 & $56.7 \pm 9.3$ & $59.3 \pm 10.4$ & $58.5 \pm 13.2$ \\
\hline Angioplasty & 15 & $55.8 \pm 9.1$ & $60.4 \pm 19.1$ & $67.0 \pm 17.8$ \\
\hline \multicolumn{5}{|c|}{ Severe LV dysfunction on GSMPI } \\
\hline $\mathrm{LVEF}<40 \% \mathrm{EDV}>140$ & 11 & $54.3 \pm 13.4$ & $26.7 \pm 7.9$ & $28.9 \pm 5.7$ \\
\hline Reduced LVEF at stress & 04 & $56.8 \pm 7.1$ & $30.5 \pm 6.9$ & $24.3 \pm 4.9$ \\
\hline Dilated LV at stress & 04 & $60.0 \pm 8.5$ & $23.3 \pm 7.2$ & $26.8 \pm 5.9$ \\
\hline \multicolumn{5}{|l|}{ Stress category } \\
\hline Dobutamine stress echo & 84 (positive in nine) & $52.6 \pm 10.2$ & $62.1 \pm 17.2$ & $63.6 \pm 17.9$ \\
\hline Exercise treadmill & 41 (positive in 12) & $50.2 \pm 8.1$ & $67.5 \pm 10$ & $70.8 \pm 9.9$ \\
\hline Adenosine stress & 60 & $50.5 \pm 11.4$ & $61.3 \pm 14.7$ & $63.1 \pm 17.5$ \\
\hline Rest MPI & 11 & $52.7 \pm 12.1$ & $43.1 \pm 18.9$ & - \\
\hline \multicolumn{5}{|l|}{ Symptom category } \\
\hline NYHA class I & 84 & $51.3 \pm 10.3$ & $60.1 \pm 15.5$ & $62.5 \pm 15.9$ \\
\hline NYHA class II & 112 & $52.3 \pm 9.9$ & $63.7 \pm 17.2$ & $66.9 \pm 17.0$ \\
\hline \multicolumn{5}{|l|}{ H/o ACS } \\
\hline No h/o ACS & 143 & $51.5 \pm 9.6$ & $65.7 \pm 14.4$ & $68.8 \pm 14.7$ \\
\hline With h/o ACS & 53 & $52.8 \pm 11.1$ & $52.3 \pm 18.2$ & $53.5 \pm 17.4$ \\
\hline \multicolumn{5}{|l|}{ Perfusion category } \\
\hline Normal Perfusion & 156 & $51.7 \pm 9.6$ & $66.6 \pm 13.6$ & $69.9 \pm 13.5$ \\
\hline Abnormal Perfusion & 40 & $52.3 \pm 11.8$ & $45.5 \pm 15.8$ & $44.9 \pm 13.4$ \\
\hline
\end{tabular}

Among the 156 patients with normal perfusion, the mean left ventricular ejection fraction (LVEF) was 66.6 \pm 11.2 and 66 had NYHA class I symptom while 90 had NYHA class II symptom (Table 2). Perfusion defect was present in 40 patients with mean LVEF of $45.5 \pm$ 15.7, of them 18 had NYHA class I symptom and 22 had NYHA class II symptom (Table 2). The Pearson Chi-square value for association between symptom class versus perfusion status is 0.094 with the two-sided asymptotic p-value being 0.76 .

Table 2: Distribution of NYHA class of symptomsaccording to perfusion status

\begin{tabular}{lll}
\hline & $\begin{array}{l}\text { Normal } \\
\text { perfusion }\end{array}$ & $\begin{array}{c}\text { Abnormal } \\
\text { perfusion }\end{array}$ \\
\hline NYHA class I & 66 & 18 \\
NYHA class II & 90 & 22 \\
\hline
\end{tabular}

Among the 53 patients with previous H/O ACS, 29 had NYHA class I symptoms and 24 had NYHA class II symptoms (Table 3). The Pearson Chi-square value for association between symptom class versus H/O ACS is 4.17 with the two-sided asymptotic p-value being 0.04 .

Table 3: Distribution of NYHA class of symptoms according to $\mathrm{h} / \mathrm{o}$ ACS

\begin{tabular}{lll}
\hline & No H/O ACS & H/O ACS \\
\hline NYHA class I & 55 & 29 \\
NYHA class II & 88 & 24 \\
\hline
\end{tabular}

Total $18(9 \%)$ patients had reversible perfusion defect on scan (no previous $\mathrm{H} / \mathrm{O}$ ACS) and $31(\sim 16 \%)$ patients despite a previous $\mathrm{H} / \mathrm{O}$ ACS had normal myocardial perfusion (Table 4).However, the Pearson Chi-square value of 19.9 with the two-sided asymptotic p-value being $<0.001$ indicates an association between perfusion status versus $\mathrm{H} / \mathrm{O}$ ACS.

Table 4: Distribution of perfusion status according to history of ACS

\begin{tabular}{lll}
\hline & No H/O ACS & H/O ACS \\
\hline Normal perfusion & 125 & 31 \\
Perfusion defect & 18 & 22 \\
\hline
\end{tabular}


To sum up, the NYHA class of symptoms was not found to be associated with GSMPI derived perfusion status ( $p$ $>0.05$ ) in this series of female patients. Additionally, the $\mathrm{H} / \mathrm{O}$ ACS was found to have strong association both with NYHA class of symptoms and with GSMPI derived perfusions status $(\mathrm{p}<0.05)$.

\section{DISCUSSION}

In this series, $14.6 \%$ was the proportion of female patients against the total patient pool undergoing GSMPI over 12 years, although with a 4.4-fold increase of the total number of patients in the year-2016, the last time point of data inclusion in comparison to year-2005, the point of the first set of data availability. The International Atomic Energy Agency Nuclear Cardiology Protocols Study Registry (6), which did not include data from Bangladesh, comprises GSMPI data from 7911 patients from 65 continents. Though the cumulated proportion of females in this study was $41 \%$ the actual proportion varied from $<25 \%$ to $\geq 55 \%$ among the countries. However, the weighted pool prevalence for cardiovascular disease was the same 3\% for both genders with a $0.12 \%$ per-year rise of prevalence over 39 years, in a recent meta-analysis of 13 studies comprising of 129,740 persons (4).

In this series, $31 \%$ of patients who were referred for GSMPI had significant coronary artery disease. In a recent series of patients undergoing diagnostic angiography in a tertiary hospital the reported proportion of normal coronary angiogram was $25 \%$ (7). The proportion of coronary revascularization was $14 \%$ with the proportion of severe LV dysfunction being $5.6 \%$ among all female patients who underwent GSMPI. The proportion of female patients was $3 \%$ in a series on coronary revascularization (8) and $4 \%$ in another series of severe LV dysfunction (5) in patients of both genders undergoing GSMPI.

The major proportion of patients underwent dobutamine stress echo in this series of symptomatic female patients, where $10.7 \%$ were found positive for inducible myocardial ischemia. Stress echocardiography is known to be of high diagnostic accuracy in women with chest pain (9) even if there is a low cardiovascular risk profile
(10) whereas its combination with GSMPI can aid decision for revascularization and prediction of prognosis (11). Among the patients undergoing exercise treadmill stress, $29 \%$ were found positive for inducible ischemia. A series from Bangladesh found the false positive rate for treadmill test in women to be $35 \%$ (12). A recent meta-analysis not only reconfirms the higher false positivity of treadmill stress in women but also assigns this attribute particularly to perimenopausal women (13), while compromised coronary perfusion in postmenopausal women may be reflected by a lower peak rate pressure product (14). Although the reduced exercise capacity in women can result from an underlying coronary microvascular dysfunction or a non-obstructive $\mathrm{CAD}(15)$, the Asian women reportedly have a mismatched prevalence of CAD with the risk factor derived pre-test probability (16). Adenosine stress was used in $30.6 \%$ of female patients as per clinical recommendation and was found to be generally well-tolerated and better accepted than the other two modalities, a fact that deserves another systematic investigation to be fitted in the routine clinical protocol.

This series fails to find an association between NYHA class of symptoms with myocardial perfusion status defined as normal or abnormal. This in turn supports the recommendation for using the 'Activities of Daily Living' or the 'Duke Activity Status Index' in combination with an 'IHD risk estimate' for evaluation of symptomatic women towards their candidacy for stress GSMPI.(17). Though there was a statistical association between the classes of symptoms and H/O ACS, the larger proportion of patients in both the class of symptoms had no previous $\mathrm{H} / \mathrm{O}$ ACS. On the contrary, $9 \%$ of all the symptomatic patients were detected with new myocardial ischemia. Paradoxically, normal myocardial perfusion in $\sim 16 \%$ despite receiving treatment for ACS indicates a non-obstructive $\mathrm{CAD}$ that is known to occur with a rate of $10-25 \%$ (1). Altogether our findings support the necessity of increasing the application of stress GSMPI in women because they, on the one end, can have more symptoms despite non-obstructive CADs, on the other end, can have a less symptomatic progression of microvascular dysfunction coexisting with metabolic disease $(1,17)$. 
Moreover, stress SPECT imaging of myocardial perfusion is appropriate in an individual of any pretest probability if the ECG is uninterpretable or there is an inability to exercise (17).

\section{CONCLUSION}

Despite the proportion of female patients undergoing GSMPI has remained low, a temporal increase in the number of patients indicates increased acceptance of GSMPI by the clinicians and patients. We recommend that the application of pharmacological stress GSMPI should further increase among women.

\section{DISCLOSURE}

No competing financial interests exist

\section{ACKNOWLEDGEMENT}

Authors acknowledge the collaborative contribution of cardiologists and cardiac surgeons to Nuclear Cardiology.

\section{REFERENCES}

1. Shaw LJ, Bugiardini R, Merz CNB. Women and Ischemic Heart Disease. Evolving Knowledge. J Am CollCardiol. 2009;54(17):1561-75. DOI:10.1016/j.jacc.2009.04.098

2. Udell JA, Koh M, Qiu F, Austin PC, Wijeysundera HC, Bagai A, et al. Outcomes of women and men with acute coronary syndrome treated with and without percutaneous coronary revascularization. J Am Heart Assoc. 2017;6(1). Available from: https://www.ahajournals.org/doi/10.1161/JAHA.116.004319

3. Bots SH, Peters SAE, Woodward M. Sex differences in coronary heart disease and stroke mortality: A global assessment of the effect of ageing between 1980 and 2010. BMJ Glob Heal. 2017;2(2):298. DOI:10.1136/bmjgh-2017-000298

4. Chowdhury MZI, Haque MA, Farhana Z, Anik AM, Chowdhury AH, Haque SM, et al. Prevalence of cardiovascular disease among bangladeshi adult population: A systematic review and meta-analysis of the studies. Vasc Health Risk Manag. 2018;14:165-81. DOI:10.2147/VHRM.S166111

5. Sarker AK, Nasreen F, Nisa L, Hussain R, Hoque H, Adhikary DK. Survival Outcome in Patients with Cardiomyopathy Detected by Gated SPECT Myocardial Perfusion Imaging. Bangladesh J Nucl Med. 2019;21(2):81-6. DOI:10.3329/bjnm.v21i2.40356

6. Shi L, Dorbala S, Paez D, Shaw LJ, Zukotynski KA, Pascual $\mathrm{TNB}$, et al. Gender Differences in Radiation Dose from Nuclear Cardiology Studies Across the World Findings from the INCAPS Registry. JACC Cardiovasc Imaging. 2016;9(4):376-84. DOI:10.1016/j.jcmg.2016.01.001
7. Islam M, Ghafur S, Barman R, Sarker H, Basunia A, Rahman $\mathrm{M}$, et al. Angiographic Studies of Coronary Artery Disease in Rangpur Medical College Hospital. Univ Hear J. 2021;17(1):55-9. DOI:10.3329/UHJ.V17I1.50882

8. Sarker AK, Nasreen F, Nisa L, Hussain R. Role of Gated SPECT MPI in Follow-up of Patients afterCoronary Revascularization. Bangladesh J Nucl Med. 2019 Dec 11;22(1):30-5. DOI:10.3329/bjnm.v22i1.40501

9. Padang R, Pellikka PA. The role of stress echocardiography in the evaluation of coronary artery disease and myocardial ischemia in women. J NuclCardiol. 2016 Oct 1;23(5):1023-35. DOI:10.1007/s12350-016-0592-2

10. Park SJ, Chung S, Chang SA, Choi JO, Choi JH, Lee SC, et al. Independent and incremental prognostic value of exercise stress echocardiography in low cardiovascular risk female patients with chest pain. Echocardiography. 2017;34(1):69-77. DOI:10.1111/echo.13388

11. Qian L, Xie F, Xu D, Porter TR. Long-term prognostic value of stress myocardial perfusion echocardiography in patients with coronary artery disease: a meta-analysis. Eur Hear J Cardiovasc Imaging. 2020;jeaa026(Online ahead of print). DOI:10.1093/ehjci/jeaa026

12. Taimur SDM, Khan SR, Islam F. Angiographic Evaluation of ETT (Treadmill) Positive Patients in a Tertiary Care Hospital of Bangladesh. Int J Med Heal Sci. 2014;8(12):851-4. DOI: 10.5281/zenodo. 1337637

13. Sun Y, Li W, Yin L, Wei L, Wang Y. Diagnostic accuracy of treadmill exercise tests among Chinese women with coronary artery diseases: A systematic review and meta-analysis. Int J Cardiol. 2017;227:894-900. DOI: 10.1016/j.ijcard.2016.11.129

14. Nagpal S, Walia L. Haemodynamic responses to exercise stress test in postmenopausal women with coronary artery disease. J Indian Med Assoc. 2013;111(1):24-7. PMID: 24000504

15. Bechsgaard DF, Hove JD, Suhrs HE, Bové KB, Shahriari P, Gustafsson I, et al. Women with coronary microvascular dysfunction and no obstructive coronary artery disease have reduced exercise capacity. Int J Cardiol. 2019;293(15):1-9. DOI:10.1016/j.ijcard.2019.07.048

16. Kim YH, Shim WJ, Kim MA, Hong KS, Shin MS, Park SM, et al. Utility of pretest probability and exercise treadmill test in Korean women with suspected coronary artery disease. J Women's Heal. 2016;25(6):617-22. DOI:10.1089/jwh.2015.5242

17. Taqueti VR, Dorbala S, Wolinsky D, Abbott B, Heller G V., Bateman TM, et al. Myocardial perfusion imaging in women for the evaluation of stable ischemic heart disease - state-of-the-evidence and clinical recommendations. J NuclCardiol. 2017 Aug 1;24(4):1402-26. DOI:10.1007/s12350-017-0926-8 